\title{
Kaedah Pembelajaran Matematika dan Kaitannya dengan Kecerdasan Interpersonal Siswa SMA Kota Makassar
}

\author{
Ahmad Talib \\ Universitas Negeri Makassar \\ email: matalibunm@yahoo.com
}

\begin{abstract}
This study aimed to examine the links between mathematical learning strategy and interpersonal intelligence of high school students at Makassar. The research method used is explorative and quantitative research. The population of this study is Makassar high school students, and the sample is students of class XI SMAN 8 Makassar and SMAN 22 Makassar. The data analysed by using descriptive and inferential statistics with analysis of variance (ANOVA). The results obtained were descriptions of students' interpersonal intelligence in experimental class is in the high category, while the descriptions of students' interpersonal intelligence in control class is in the low and middle category. The results of inferential statistical analysis shows that students' interpersonal intelligence at Makassar high school in experimental class is better than the students' interpersonal intelligence in control class, this means there is a link between mathematical learning strategy and interpersonal intelligence of high school students at Makassar.
\end{abstract}

Keywords: Interpersonal Intelligence, Cooperative Learning Model, Analysis of Variance (ANOVA)

\section{PENDAHULUAN}

Tujuan pendidikan nasional pada hakikatnya di samping mengedepankan pembangunan SDM yang berkualitas dan berdaya saing, juga diarahkan untuk meningkatkan kualitas SDM untuk mendukung terwujudnya masyarakat yang berharkat, bermartabat dan berakhlak mulia, menjunjung tinggi nilai-nilai agama, karakter dan persatuan bangsa serta menghargai keberagaman dengan tetap berlandaskan pada norma kehidupan masyarakat Indonesia yang religius, berbudaya dan berkarakter positif (Depdiknas, 2008). Dalam domain afektif, kaedah pembelajaran belum berhasil untuk mengembangkan kecerdasan interpersonal siswa. Kecerdasan ini berkaitan dengan kesadaran dan pengetahuan siswa tentang cara hidup bersama dengan damai, saling membantu satu sama lain dan berinteraksi secara positif dengan orang lain dalam lingkungan sosial (Gardner, 2003).

Matematika merupakan salah satu mata pelajaran yang penting dan dipelajari oleh semua siswa di setiap jenjang sekolah. Matematika juga dikatakan sebagai salah satu mata pelajaran yang sukar difahami oleh kebanyakan siswa. Hasil ujian nasional (UN) menunjukkan bahwa penguasaan matematika di kalangan siswa sekolah menengah berada pada kategori yang rendah. Laporan Badan Standar Nasional Pendidikan (BSNP) tahun 2006-2008 menunjukkan bahwa mutu pendidikan matematika yang diwakili dengan nilai ratarata masih rendah, pencapaian matematika ini pada tingkat nasional, regional dan daerah masih tertinggal jika dibandingkan dengan mata pelajaran yang lain (Depdiknas, 2008).

Pada aspek non kognitif, ternyata kondisi objektif menunjukkan bahwa siswa hari ini menampakan adanya gejala degradasi dan dekadensi moral, fenomena tersebut dapat dicermati dari banyaknya masalahmasalah sosial di tengah kehidupan sekolah dan masyarakat, dapat dilihat pula pada banyaknya demonstrasi yang cenderung anarkis, serta meluasnya tindak kekerasan dan fornografi siswa pada media HP, seks bebas, juga dapat dilihat begitu banyaknya siswa sekolah menengah yang terlibat pada kasus narkoba, geng motor, tawuran antar siswa dan aktivitas kriminal lainnya (Talib, 2014).

Alternatif yang banyak dikemukakan untuk mengatasi, paling tidak mengurangi, masalah di atas adalah pendidikan. Pendidikan yang identik dengan aktivitas pembelajaran di sekolah, dianggap sebagai preventif, proses pembelajaran di sekolah diharapkan dapat mengembangkan kualitas afektif atau karakter

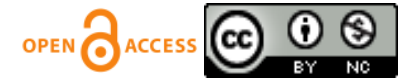


positif siswa dalam berbagai aspek yang dapat memperkecil dan mengurangi penyebab berbagai masalah budaya dan masalah penyakit sosial (Talib, 2014). Memang diakui bahwa hasil dari pendidikan akan terlihat dampaknya dalam waktu yang tidak sekejap, tetapi harus dilakukan sekarang juga, karena memiliki daya tahan dan dampak yang kuat pada keharmonisan interaksi sosial di sekolah dan di tengah masyarakat.

Karakter positif, nilai afektif atau nilai-nilai luhur dan akhlak yang mulia siswa mestinya bukan hanya semata-mata menjadi tanggung jawab pelajaran agama, PKN, pendidikan karakter dan pelajaran berbasis akhlak lainnya, namun saatnya menjadi tanggung jawab bersama semua mata pelajaran di sekolah. Setiap mata pelajaran, termasuk mata pelajaran matematika harus memberikan dampak pengiring yang positif terhadap berkembangnya ranah afektif yang sesuai dengan karakter dan tatanan budaya, yakni berkembangnya kecerdasan interpersonal dalam pembelajaran matematika, diharapkan strategi ini dapat membantu mengeliminasi atau paling tidak mengurangi degradasi moral siswa, sehingga dapat membangun nilai afektif, karakter positif dan budi pekerti luhur siswa.

Sebagaimana yang dirasakan sehari-hari, bahwa dalam aspek kecerdasan berbasis afektif, pendidikan di sekolah menengah gagal mewujudkan karakter positif siswa, fenomena ini boleh dilihat daripada tingkah laku siswa yang menandakan gejala kemerosotan dan keruntuhan moral, yaitu seks bebas, narkoba, membuli, perkelahian antara siswa, unjuk rasa yang anarkis, siswa yang terlibat dalam budaya tawuran, geng motor (begal) dan aktivitas kenakalan remaja lainnya (Eny, 2012). Salah satu faktor kegagalan tersebut adalah penggunaan strategi pembelajaran yang tidak diarahkan untuk mengembangkan kecerdasan interpersonal atau kecerdasan sosial siswa. Strategi pembelajaran sekarang ini kurang sesuai dengan kaedah pembelajaran yang melibatkan semua siswa, baik kemampuan berpikir maupun kerja sama secara tim dalam menyelesaikan masalah (Barrett, T., Cashman, D., 2010). Strategi pembelajaran tradisional (PT) masih terus diterapkan oleh guru di sekolah menengah, dengan strategi ini sesorang guru hanya sekedar memberi sebahagian informasi ke dalam pikiran siswa tanpa mengenalpasti apakah konsep yang diterangkan dapat diterima siswa atau tidak. Usaha mendapatkan konsep matematika yang jelas, haruslah diusahakan oleh siswa itu sendiri secara aktif dan berkelanjutan (Hui, et al., 2011; Nandal, 2011).

Keadaan proses pembelajaran di sekolah menengah dewasa ini, menunjukkan bahwa siswa kurang mengoptimalkan kemampuan mereka dalam menyelesaikan masalah, dan bekerjasama secara berkelompok dalam proses pembelajaran matematika, sementara hasilnya sangat bergantung kepada kebolehan siswa untuk belajar secara tim dalam kelompok (Basri, 2009). Usaha untuk meningkatkan kemampuan menyelesaikan masalah dan belajar secara berkelompok merupakan perkara yang harus dititikberatkan oleh pihak sekolah sekarang ini. Untuk meningkatkan kualitas dan menyesuaikan strategi pembelajaran agar mengikuti perkembangan terkini, maka kelemahan para siswa perlu dikenali pada peringkat awal supaya program penguatan dan pengayaan dapat dilakukan secepatnya.

Strategi pembelajaran yang diterapkan oleh guru tidak tepat, malah kaedah pembelajaran yang diterapkan juga tidak membantu mengembangkan kecerdasan afektif, terutama kecerdasan interpersonal siswa. Penerapan kaedah pembelajaran matematika yang tepat diyakini dapat mengembangkan kecerdasan interpersonal siswa, dampak daripada strategi ini akan menghasilkan siswa yang tidak saja cemerlang secara kognitif, tetapi juga cemerlang di dalam domain afektif atau kecerdasan interpersonal (Wan Zah Wan Ali, et al., 2005; Mohd Uzi Dollah \& Lim, 2009). Dengan demikian penerapan kaedah pembelajaran matematika yang tepat, yang mengandung strategi menyelesaikan masalah, menyusun alternatif penyelesaian, diikuti proses dan diakhiri dengan kesimpulan yang mantap dan tepat, melalui kerja sama secara berkelompok dalam suasana kooperatif. Semua aktivitas pembelajaran tersebut dapat menjadikan siswa untuk terus berhasil dalam proses pembelajaran selanjutnya, dan itu merupakan tanda-tanda proses berkembangnya kecerdasan afektif (Santyasa, 2008), terutama proses berkembangnya kecerdasan interpersonal siswa.

Pendidikan adalah investasi sumber daya manusia jangka panjang yang mempunyai nilai strategis bagi kelangsungan peradaban alternatif yang bersifat preventif karena pendidikan menumbuhkan integrasi nasional dan harmoni sosial, sehingga dapat membangun generasi baru bangsa yang lebih baik. Sebagai alternatif yang bersifat manusia di dunia. Pendidikan berfungsi untuk mencetak sumber daya manusia (SDM) yang mampu bekerja serta mampu mengoptimalkan kemampuan berpikir dalam menjalankan pekerjaannya. Guna mencapai fungsi tersebut, maka saat ini haruslah ditekankan pada upaya-upaya peningkatan mutu pendidikan yang menjadi bagian terpadu dari upaya peningkatan kualitas manusia, baik aspek kemampuan, 
kepribadian, maupun tanggung jawab sebagai warga masyarakat. Indonesia menempatkan pendidikan sebagai sesuatu yang penting dan utama. Hal ini dapat dilihat dari isi Pembukaan UUD 1945 alinea IV yang menegaskan bahwa salah satu tujuan nasional bangsa Indonesia adalah mencerdaskan kehidupan bangsa.

Agar dunia pendidikan mampu melahirkan manusia-manusia yang sesuai dengan tuntutan pembangunan maka sistem pendidikan Indonesia harus mempunyai kualitas pengajaran yang baik. Pengajaran yang baik dalam arti peserta didik yang melakukan kegiatan belajar mempunyai minat dan semangat belajar yang tinggi serta mampu merangsang siswa agar aktif berpartisipasi dalam kegiatan belajar sehingga hasil belajar pun juga seperti yang diharapkan dan tujuan pembelajaran yang diinginkan dapat tercapai secara efektif dan efisien.

Matematika merupakan ilmu universal yang mendasari perkembangan teknologi modern, mempunyai peran penting dalam berbagai disiplin ilmu dan mengembangkan daya pikir manusia (Depdiknas, 2006). Mengingat pentingnya matematika sebagai ilmu dasar, maka pembelajaran matematika di berbagai jenjang pendidikan perlu mendapat perhatian yang serius. Dengan demikian, guru sebagai pelaksana pembelajaran harus mampu menerapkan cara yang efektif dan efisien agar tujuan pembelajaran dapat dilaksanakan secara optimal.

Tujuan matematika yang hendak dicapai adalah siswa mampu menggunakan matematika yang dipelajarinya dalam kehidupan sehari-hari dan dalam pelajaran lain yang memanfaatkannya. Namun kenyataan di beberapa sekolah SMA di Makassar, mata pelajaran matematika adalah salah satu mata pelajaran yang masih dianggap sulit oleh siswa bahkan dibenci. Hal ini timbul oleh karena keabstrakan matematika terkadang sulit untuk dicerna siswa. Disamping itu, berdasarkan wawancara dengan guru bidang studi matematika diperoleh informasi bahwa di sekolah tersebut masih selalu menggunakan model pembelajaran langsung (atau sering disebut juga pembelajaran tradisional) dengan metode ceramah, tanya jawab dan penugasan tanpa adanya variasi dan menurut mereka diperlukan model pembelajaran kooperatif, misalnya Model Pembelajaran Kooperatif Tipe Course Review Horay (CRH), sebab tipe ini mengandung permainan yang sangat mungkin disukai siswa.

Model pembelajaran langsung yang dilakukan terus menerus tanpa adanya variasi oleh guru bidang studi matematika di sekolah tersebut menyebabkan sebagian besar siswa hanya menjadi peserta yang pasif karena siswa kurang diberi kesempatan untuk berperan aktif dalam proses pembelajaran, suasana kelas terasa monoton dan tidak menyenangkan sehingga siswa cepat bosan dan malas mengikuti pelajaran yang berakibat pada rendahnya hasil belajar siswa. Keadaan siswa pasif dapat dilihat pada saat guru menjelaskan materi siswa cenderung diam, hanya mendengarkan penjelasan dari guru, kurang berani memberikan pendapat pada saat guru memberikan pertanyaan, atau menanggapi jawaban teman lainnya, bahkan takut bertanya walaupun sebenarnya belum paham tentang apa yang dipelajari, tidak merespons saat guru menyajikan pekerjaan yang keliru, siswa hanya mengerjakan atau mencatat apa yang diperintahkan oleh guru. Bila keadaan ini dilakukan terus-menerus tanpa adanya variasi akan menyebabkan siswa menjadi bosan dan jenuh dalam mengikuti pembelajaran, siswa malas untuk belajar matematika, siswa merasa tidak termotivasi untuk belajar matematika sehingga hasil belajar matematika menurun dan cenderung dibawah rata-rata.

Dari permasalahan tersebut munculah suatu pemikiran untuk menggunakan model pembelajaran (atau sering disebut juga kaedah pembelajaran) yang inovatif dan kreatif yang dapat mengaktifkan siswa dalam proses pembelajaran serta membuat suasana kelas yang menyenangkan dan meriah agar siswa termotivasi untuk belajar dikarenakan salah satu faktor penentu keberhasilan belajar adalah faktor model pembelajaran. Model pembelajaran merupakan langkah bagaimana seorang guru dapat menyampaikan materi ajar dan membantu siswa mencapai tujuan pembelajaran sesuai dengan apa yang telah direncanakan. Untuk mengatasi masalah yang terjadi di sekolah SMA di Makassar salah satu alternatif solusi yang bisa dilakukan adalah menggunakan model pembelajaran Cooperative Learning yang di dalam proses pelaksanaanya lebih berpusat pada siswa (student oriented).

Dalam model pembelajaran Cooperative Learning memungkinkan siswa untuk terlibat aktif dalam proses pembelajaran. Pembelajaran kooperatif diajarkan keterampilan-keterampilan khusus agar siswa dapat bekerja sama dengan baik dalam kelompok-kelompoknya sehingga memiliki dampak positif terhadap siswa, karena dapat menumbuhkan keaktifan siswa agar tidak mengalami kejenuhan dan ketidaktertarikan terhadap matematika sehingga siswa jadi semangat untuk belajar matematika dan dapat memperkuat daya ingat siswa 
terhadap materi yang dipelajari yang pada akhirnya meningkatkan hasil belajar. Ada beberapa model pembelajaran kooperatif seperti : Course Review Horay.

Pada pembelajaran CRH aktivitas belajar lebih banyak berpusat pada siswa. Suasana belajar dan interaksi yang menyenangkan membuat siswa lebih menikmati pelajaran sehingga siswa tidak mudah bosan untuk belajar. Model ini merupakan cara belajar-mengajar yang lebih menekankan pada pemahaman materi yang diajarkan guru dengan menyelesaikan soal-soal. Dalam aplikasinya model pembelajaran kooperatif tipe Course Review Horay tidak hanya menginginkan siswa untuk belajar keterampilan dan isi akademik. Model pembelajaran tipe Course Review Horay juga melatih siswa untuk mencapai tujuan-tujuan hubungan sosial yang pada akhirnya mempengaruhi hasil belajar siswa.

Pada hakikatnya model pembelajaran kooperatif tipe Course Review Horay ini adalah suatu model pembelajaran yang diutamakan untuk bermain sambil belajar dengan selalu menjaga keefektifan pembelajaran, maka dari itu penerapan model pembelajaran kooperatif ini cocok untuk diterapkan pada siswa SMA yang menurut psikologinya dalam tahap perubahan menuju pencapaian belajar maksimal dengan mengadakan kegiatan belajar yang tetap menyenangkan sehingga dapat diarahkan dalam tahapan model kooperatif tersebut.

Model kooperatif tipe Course Review Horay merupakan salah satu pembelajaran kooperatif kegiatan belajar mengajar dengan cara pengelompokan siswa kedalam kelompok-kelompok kecil dan suatu pembelajaran pengujian terhadap pemahaman konsep siswa menggunakan kotak yang diisi dengan soal dan diberi nomor untuk menulis jawabannya. Siswa yang paling terdahulu mendapat tanda $(\sqrt{ })$ vertikal atau horizontal, atau diagonal harus berteriak hore atau yel-yel lainnya. Suprijono (2009).

Dari hasil penelitian yang telah dilakukan oleh Mustaghfiroh (2010) dengan judul "Upaya Meningkatkan Motivasi Belajar Siswa Melalui Diskusi Course Review Horay Di Kelas VIIB SMP IT Madjid Syuhada Yogyakarta" menyimpulkan bahwa: (1) penggunaan diskusi Course Review Horay dalam pembelajaran matematika dapat meningkatkan motivasi belajar siswa di kelas VIIB SMP IT Masjid Syuhada, (2) peserta didik lebih optimis dan tidak takut salah dalam menjawab pertanyaan dari guru, (3) peserta didik juga mampu bekerjasama dalam satu kelompok dalam berdiskusi.

Dengan model pembelajaran ini diharapkan dapat melatih kerja sama dalam menyelesaikan masalah dengan pembentukan kelompok, pembelajarannya menarik dan mendorong siswa untuk terjun ke dalamnya, tidak monoton karena diselingi sedikit hiburan sehingga suasana tidak menegangkan serta siswa lebih semangat belajar karena suasana pembelajaran berlangsung menyenangkan sehingga mampu membantu siswa dalam meraih nilai tinggi.

Berdasarkan latar belakang yang telah dipaparkan di atas dan dari hasil penelitian sebelumnya, sehingga peneliti mengkaji penelitian Pembelajaran Matematika dan Kaitannya dengan Kecerdasan interpersonal Siswa SMA Kota Makassar.

Dengan memperhatikan judul di atas, maka dikaji mengenai pengaruh kaedah pembelajaran atau model kooperatif tipe Course Review Horay (CRH) terhadap kecerdasan interpersonal siswa dalam pembelajaran matematika. Dalam penelitian ini dilakukan eksperimen kaedah pembelajaran model kooperatif tipe Course Review Horay (CRH) pada sekolah SMA Negeri 8 Makassar dan kaedah pembelajaran tradisional dengan pengajaran langsung pada sekolah SMA Negeri 22 Makassar.

\section{METODE}

Metode penelitian yang digunakan adalah metode penelitian eksploratif dan metode penelitian kuantitatif. Populasi penelitian yaitu siswa SMA Kota Makassar dan sampel penelitian yaitu siswa kelas XI SMA Negeri 8 Makassar dan SMA Negeri 22 Makassar Tahun Pelajaran 2016/2017. Teknik analisis data yang digunakan yaitu statistik deskriptif dan statistik inferensial dengan analisis variansi (ANOVA).

\section{HASIL DAN PEMBAHASAN}


Hasil analisis statistika deskriptif menunjukkan bahwa kecerdasan interpersonal siswa kelas eksperimen yang diajar dengan menggunakan kaedah pembelajaran kooperatif tipe Course Review Horay dikategorikan tinggi yang tampak dari skor rata-rata.

Kecerdasan interpersonal siswa kelas kontrol yang diajar dengan kaedah pembelajaran langsung dengan pengajaran tradisional dikategorikan sedang dan rendah yang tampak dari skor rata-rata.

Hasil analisis inferensial menunjukkan bahwa setelah diberikan perlakuan, terdapat perbedaan kecerdasan interpersonal siswa yang diajar dengan menggunakan kaedah pembelajaran kooperatif tipe Course Review Horay dengan siswa yang diajar dengan menggunakan model pembelajaran langsung. Kecerdasan interpersonal siswa yang diajar dengan kaedah pembelajaran kooperatif tipe Course Review Horay lebih baik/lebih tinggi dibandingkan dengan kecerdasan interpersonal siswa kelas yang diajar dengan model pembelajaran langsung. Hal ini ditunjukkan oleh nilai $\operatorname{sig}(1$-tailed $)=0,00$ atau $p-$ value $=0,00$ yang lebih kecil dari $\alpha=0,05$.

Adanya perbedaan yang signifikan pada penggunaan kaedah pembelajaran kooperatif tipe Course Review Horay karena berdasarkan kajian teori yang menyatakan bahwa pada pembelajaran dengan menerapkan kaedah pembelajaran kooperatif tipe Course Review Horay, siswa senantiasa dapat berperan secara aktif dan inovatif serta membuat suasana belajar menjadi lebih menyenangkan. Hal ini dikarenakan kaedah pembelajaran kooperatif tipe Course Review Horay merupakan model pembelajaran yang dapat menciptakan suasana kelas menjadi meriah dan menyenangkan.

Dalam kaedah pembelajaran kooperatif tipe Course Review Horay siswa dikelompokkan menjadi beberapa kelompok kecil. Masing-masing anggota kelompok saling membantu dan memberikan ide-idenya dalam menyelesaikan soal yang terdapat dalam LKS yang dibagikan tiap kelompok. Pembelajaran secara kelompok juga dapat meningkatkan interaksi sosial siswa dan mempertinggi rasa toleransi. Hal ini menjadikan siswa tidak lagi bertindak pasif, menerima dan menghafal konsep yang diberikan oleh guru, sehingga siswa menjadi lebih kritis dan kreatif dalam mengembangkan ide-ide serta konsep-konsep matematika.

\section{KESIMPULAN}

Kecerdasan interpersonal siswa pada kelas eksperimen yang diajar dengan menggunakan kaedah pembelajaran kooperatif tipe Course Review Horay dikategorikan tinggi, sementara pada kelas kontrol yang diajar dengan kaedah pembelajaran langsung dengan pengajaran tradisional dikategorikan rendah dan sedang.

Kaedah pembelajaran kooperatif tipe Course Review Horay berpengaruh positif terhadap kecerdasan interpersonal siswa SMA Kota Makassar dalam hal ini kecerdasan interpersonal siswa SMA Kota Makassar yang diajar dengan kaedah pembelajaran kooperatif tipe Course Review Horay lebih baik dibandingkan dengan kecerdasan interpersonal yang diajarkan dengan kaedah pembelajaran langsung dengan pengajaran tradisonal. Hal tersebut menunjukkan bahwa terdapat kaitan antara kaedah pembelajaran matematika dengan kecerdasan interpersonal siswa SMA Kota Makassar.

\section{DAFTAR PUSTAKA}

Barrett, T., Cashman, D. (Eds). 2010. A Practitioners' Guide to Enquiry and Problem-Based Learning. Dublin: UCD Teaching and Learning.

Basri, Muhammad. 2009. Keefektifan Model Pembelajaran Kooperatif Tipe Jigsaw pada Pembelajaran Matematika Kelas X Di SMA Negeri 1 Makassar. Tesis Magister tidak diterbitkan: PPs UNM Makassar

Depdiknas. 2006. Standar Isi Mata Pelajaran Matematika SMA dan Madrasah Aliyah. Jakarta: Direktorat Jenderal Peningkatan Mutu Pendidik dan Tenaga Kependidikan.

Depdiknas. 2008. Penulisan Modul. Direktorat Tenaga Kependidikan, Direktorat Jenderal PMPTK Jakarta: Depdiknas. 
Eny. 2012. Pendidikan Karakter Penting dan Perlu. BEM Keluarga Farmasi UGM. 2 May 2012. Tersedia: http://bemkmfaugm.wordpress.com/2012/ 05/02/ pendidikan-karakter-penting-dan-perlu/ [19 February 2013].

Gardner, H. 2003. Multiple Intelligences. New York: Basic Books Harper. Collins Publ. Inc.

Hui, Chuan Li., Smith, C. (Ed.) 2011. The Development Of Taiwanese Students' Understanding Of Fractions: A Problem Based Learning Approach. Proceedings of The British Society for Research into Learning Mathematics 31(2) June.

Mohd Uzi Dollah \& Lim, Chap Sam. (2009). Penerapan Nilai Pendidikan Matematik dalam Pengajaran Matematik Di Sekolah Menengah. Jurnal Sains dan Matematik Vol.1 No.2 (2009) 29-40.

Mustaghfiroh. 2010. Upaya meningkatkan motivasi belajar siswa melalui diskusi Course Review Horay Di Kelas VIIB SMP IT Masjid Syuhada Yogyakarta. Lomba Inovasi Pembelajaran Bagi Guru Tingkat Kota Yogyakarta Tahun 2010.

Nandal, Sanjay. (2011). Effectiveness Analysis Of Problem Based Learning Vs Traditional Lecture Method. Journal of Applied Management \& Computer Science, V. 3 August, Rothak: Institute of Management Studies \& Research MDU

Santyasa, I Wayan. 2008. Pembelajaran Berbasis Masalah dan Pembelajaran Kooperatif. Makalah Disajikan dalam Pelatihan tentang Pembelajaran dan Asesmen Inovatif, Tanggal 22-24 Agustus. Universitas Pendidikan Ganesha

Suprijono, Agus. 2009. Cooperative Learning Teori dan Aplikasi PAIKEM. Surabaya: Pustaka Pelajar.

Talib, Ahmad. 2014. Problem Based Learning in Cooperative Situation (PBLCS) and Its Impact on Development of Personal Intelligence. International Journal of Evaluation and Research in Education (IJERE). Volume 3 No.4, December 2014 ISSN: 2252-8822, Yogyakarta: Universitas Ahmad Dahlan Yogyakarta Indonesia.

Wan Zah Wan Ali, et al. 2005. Kefahaman Guru Tentang Nilai Matematik. Jurnal Teknologi, 43(E) Dis. 2005: 45-62. UTM Malaysia. 